\title{
HARDY'S INEQUALITY FOR JACOBI EXPANSIONS
}

\author{
YUICHI KANJIN AND KUNIO SATO
}

Abstract. If an analytic function $F(z)=\sum_{n=0}^{\infty} a_{n} z^{n}$ belongs to the Hardy space on the unit disc, then the sequence of coefficients satisfies $\sum_{n=0}^{\infty}\left|a_{n}\right| /(n+1)<\infty$, which is well-known as Hardy's inequality. This type of inequality is obtained with respect to the Jacobi expansions.

Mathematics subject classification (2000): 42C10, 42B30, 33C45.

Key words and phrases: Hankel transform, transplantation theorem, Hardy space.

\section{REFERENCES}

[1] R. R. CoIfMAn AND G. Weiss, Extensions of Hardy spaces and their use in analysis, Bull. Amer. Math. Soc. 83 (1977) 569-645.

[2] G. H. HARDY AND J. E. LitTLEWOOD, Some new properties of Fourier constants, Math. Ann. 97 (1926), 159-209.

[3] Y. Kanjin and K. Sato, Paley's inequality for the Jacobi expansions, Bull. London Math. Soc. 33 (2001), 483-491.

[4] G. SzEGÖ, Orthogonal Polynomials, Amer. Math. Soc. Colloquium Publ. XXIII (4th edn, Amer. Math. Soc., Providence, RI, 1975). 